\title{
Determination of the apparent charge of natural organic matter
}

\author{
Do Hee Kim ${ }^{1, *}$, H.K. Shon ${ }^{2}$, S. Phuntsho ${ }^{2}$ and J. Cho ${ }^{3}$
}

${ }^{1}$ Department of Urban Environment, Incheon Development Institute, San 64-1, Simgok-

Dong, Seo-Gu, Incheon 404-190, Korea, Tel.: +82 (32) 260-2665; Fax: +82 (32) 260-

2669

${ }^{2}$ School of Civil and Environmental Engineering, Faculty of Engineering and Information Technology, University of Technology, Sydney (UTS), Broadway, PO Box 123, Sydney, Australia

${ }^{3}$ Department of Environmental Science and Engineering, Gwangju Institute of Science and Technology (GIST)

*Corresponding author: dkim@idi.re.kr

\section{ABSTRACT}

The charge of natural organic matter (NOM) is an important parameter for understanding the membrane fouling and NOM removal mechanism with charged membrane. However, there is a lack of technology to make direct measurement of the NOM charge. In this study, we report a novel concept of measuring an apparent charge 
of the NOM using selectivity coefficient. The apparent charges of three different NOM containing different structures were evaluated to validate this proposed method. The apparent charge of the NOM exhibited a good correlation with specific UV absorbance of the NOM. This apparent charge is therefore a useful indicator for predicting the membrane fouling and NOM removal in membrane filtration technology.

Key words; Apparent charge, anion exchange (AIX) membrane, natural organic matter (NOM), selectivity coefficient

\section{INTRODUCTION}

The application of membranes for water and wastewater is becoming increasingly popular however membrane fouling is seen as a major obstacle. Fouling is a phenomenon which decreases the permeability (permeate flux) and the productivity of the membrane in the process creating additional resistance to the filtration process. The mechanisms responsible for flux reduction are concentration polarization pore blocking, cake formation and adsorption [1]. However, the actual causes of membrane fouling is considered to be a result of complex phenomenon involving many parameters such as feed water characteristics, operational parameters and the properties of the membrane itself. 
One of the significant contributing factors to membrane fouling is the property of the feed water, most of which contain natural organic matter (NOM) and inorganic matter present either in dissolved forms or in particulate forms. NOM in drinking water sources exists in heterogeneous nature, and therefore may contain aromatic and aliphatic macromolecules with different molecular weights, charge density and structure. NOM mainly includes humic substances, which are complex macromolecular products from the chemical and biological degradation of plant and animal residues including lignin, carbohydrates, and proteins [2]. Humic substances are not only problematic to membrane fouling but are also the precursors to the formation of disinfection byproducts such as trihalomethanes in drinking water treatment and biological growth in the water distribution network $[3,4]$. NOM has been reported by many researchers to be the major membrane foulants, so the determination of the fouling and removal mechanisms, due to NOM has become one of the main research topics in the field of membrane study $[5,6]$.

NOM characteristics that are of interest to membrane fouling include hydrophobicity and charge density $[7,8]$. The solution chemistry plays a significant role in the rejection and fouling in the membrane process and therefore the NOM charge density can be used 
as an important indicator to predict membrane fouling [8-11]. Many researchers have used charge repulsion and charge interaction to interpret the mechanisms of membrane fouling and NOM removal [6, 8, 9]. However, most used zeta potential as an investigation method to determine the membrane charge due to lack of other appropriate methods to measure the NOM charge. Some researchers have even used the acidity (functionality) or humic content as an indicator for the NOM charge. Therefore, if the NOM charge is measured in terms of a relative charge number, it could be used as an important indicator for predicting NOM rejection and membrane fouling via charge attraction and repulsion. The NOM charge is caused due to the presence of functional groups such as carboxyl and hydroxyl groups. These two functional groups (i.e. carboxyl and hydroxyl group) have negative charge. Therefore based on the feed solution chemistry, it would seem that almost all NOM is negatively charged [12] because these two functional groups form the major components of NOM in water.

NOM acids, including hydrophobic and hydrophilic acids, are believed to move towards anion exchange (AIX) membrane surface, due to their negative charges [13-17]. Therefore, in this study, we report the concept in the application of this principle to develop a protocol for the determination of the apparent charge of NOM, using AIX 
membrane and its selectivity coefficient.

\section{THEORY}

The apparent charge of NOM can be measured by the relationship between the (AIX) membrane and NOM charge. The reaction of NOM with an AIX membrane is expected to be similar to Eq. (1):

$$
\frac{1}{k} \mathrm{NOM}^{-k}+\overline{\mathrm{Cl}}^{-} \rightarrow \frac{1}{k} \overline{\mathrm{NOM}}^{-k}+\mathrm{Cl}^{-}
$$

where $k$ is the charge on the NOM and the $\overline{C l}$ and $\overline{N O M}$ indicates concentrations in the membrane phase.

From the selectivity equation (Eq. 2), the apparent charge of the NOM can be calculated

$$
K=\frac{[\overline{N O M}]^{-k} \cdot\left[\mathrm{Cl}^{-}\right]}{[N O M]^{-k} \cdot\left[\overline{C l}^{-}\right]}
$$

where $K$ is the selectivity, $k$ the NOM charge, $\left[\mathrm{Cl}^{-}\right]$the concentration of $\mathrm{Cl}^{-}$and $[\mathrm{NOM}]$ the concentration of NOM while $\overline{C l}$ and $\overline{N O M}$ indicates the concentrations in the membrane phase. Under the equilibrium conditions, the apparent charge of NOM can be 
calculated using Eq. (2) and the apparent charge measured as explained below.

The AIX membrane was first cut into several pieces of approximately $20 \mathrm{~cm}^{2}(13 \mathrm{mg}$ of dried weight) and then soaked in $5 \mathrm{M} \mathrm{NaCl}$ in order to replace all the mobile ions with chloride ions. Different concentrations of NOM were prepared using deionized water and AIX membranes were soaked in each of the prepared NOM solutions. Samples in the solution phase were collected after 24 hours of soaking following which the tests and the concentrations of NOM and chloride ions were measured. These measured values were taken as the concentrations in the solution phase. The membrane was then soaked in $0.1 \mathrm{M} \mathrm{NaOH}$ solution for extracting ions. The samples were then analyzed and the measured values were taken as the concentrations in the membrane phase. The apparent charge of the NOM was finally calculated using Eq. (2).

\section{MATERIALS AND METHODS}

\subsection{Natural organic matter (NOM)}

The NOM used in this study came from the Nakdong River, and is abbreviated as NR-

NOM. The Nakdong River water contains approximately $40 \sim 50 \%$ wastewater discharged from the upstream wastewater treatment plants. Before the analytical tests, 
the Nakdong River sample was concentrated by RO (BF, SAEHAN, KOREA) membrane, and stored at $4^{\circ} \mathrm{C}$ in the refrigerator. In addition, two commercially available NOM (AL-NOM, Aldrich, USA) and Suwannee River Humic Acid (SR-NOM, international humic substance society (IHSS)) were used for a comparison.

\subsection{Membranes used}

The fundamental characteristics of the AIX membrane used in this study are described in Table 1.

\subsection{Experimental protocols}

The experiments in this study consisted of two parts. The first part was the characterization and fractionation of NOM from three different sources in terms of their size, structure and functionality. The second part of the experiments was conducted to determine the apparent charge of the NOM from various sources, and their structures using selectivity coefficients.

\subsection{NOM characterization}

DOC and UV absorbance (254 nm), were measured using a TOC analyzer (Sievers 820, Sievers, USA) and UV 1640 (Shimadzu, Japan), respectively. All the samples were filtered using $0.45 \mu \mathrm{m}$ cellulose acetate filter prior to measurement. The charge densities 
of the NOM were determined by acidity measurement using a potentiometric titration (702 SM Titrino, Metrohm, USA). The NOM structures were characterized into hydrophobic, transphilic, and hydrophilic NOM using XAD-8/4 resins.

The molecular weight (MW) distribution of the NOM was calculated by high performance liquid chromatography-size exclusion chromatography (HPLC-SEC, Water 510, Waters, USA), with a SEC column (protein-pak 125, Waters, Milford, U.S). All the samples were pre-filtered using $0.45 \mu \mathrm{m}$ filter prior to HPLC-SEC analysis in order to protect the column [18]. Standard solutions of different polystyrene sulfonate (PSS) with known MW (0.25 k, $1.8 \mathrm{k}, 4.6 \mathrm{k}$, and $8.0 \mathrm{k} \mathrm{Da})$ were used to calibrate the equipment. The number-averaged molecular weight $M_{n}$, called as "median", was calculated using the equation below.

$$
M_{n}=\sum_{i=1}^{n}\left(N_{i} M_{i}\right) / \sum_{i=1}^{n}\left(N_{i}\right)
$$

The weight-averaged molecular weight was determined using the following equation:

$$
M_{w}=\sum_{i=1}^{n}\left(N_{i} M_{i}^{2}\right) / \sum_{i=1}^{n}\left(N_{i} M_{i}\right)
$$

Where $N_{i}$ is the number of molecules having a molecular weight $M_{i}$ and $i$ is an incrementing index over all molecular weights present. Polydispersity is the ratio of 
weight-averaged molecular weight to number-averaged molecular weight.

Each NOM was fractionated into colloidal NOM (COM) and non-colloidal NOM (NCOM), using a dialysis bag (MWCO of $3.5 \mathrm{kDa}$ ). The N-COM was further fractionated into hydrophobic (HP, XAD 8 absorbable), transphilic (TL, XAD 4 absorbable) and hydrophilic (HL, neither XAD 8 nor XAD 4 absorbable) NOM [19-21]. Six different NOM concentrations $(0.000,0.002,0.004,0.006,0.008$ and $0.010 \mathrm{M})$ were used with the same total ion condition for each test. The ionic strength was adjusted with $0.01 \mathrm{M}$ $\mathrm{NaCl}$.

\subsection{Membrane Characterization}

The AIX membrane (Model AMX, NEOSEPTA, Japan) used in this study was characterized in terms of zeta potential and ion exchange capacity. The zeta potential was measured electrophoretically using commercially available apparatus (ELS 8000, Otzca, Japan) and polylatex in $10^{-3} \mathrm{M} \mathrm{NaCl}$ solution as a standard particle. The membrane was placed in $5 \mathrm{M} \mathrm{NaCl}$ solution and then soaked in $0.1 \mathrm{M} \mathrm{NaOH}$ solution, which exchanged the chloride for hydroxyl ions. The ion capacity was then estimated by measuring the amount of detached chloride ions in terms of meq/g of dried membrane. 


\section{RESULTS AND DISCUSSION}

\subsection{NOM characteristics}

Table 2 shows the MW of NOM from the three different sources. Each NOM exhibited a different molecular weight (MW) and polydiversity $\left(M_{w}\right.$ (weight averaged $\left.M_{w}\right) / M_{n}$ (number averaged MW)), based on the HPLC-SEC method. The COM had the largest and the HL-NOM the smallest MW value of all the NOM structures. The SR-NOM and AL-NOM showed relatively larger MW values than the NR -NOM.

The DOC, $\mathrm{UVA}_{254}$ and SUVA values for each NOM fraction from each nNOM source are summarized in Table 3. Each NOM fraction exhibited different DOC, $\mathrm{UVA}_{254}$ and SUVA values, as well as different MW sizes and distributions. The HP-NOM and TLNOM were mostly composed of hydrophobic and hydrophilic acids, respectively. This implies that a negatively charged membrane would preferentially reject these constituents because of the charge density of acidic functional groups (NOM acidity). However, the COM and HL-NOM were mainly neutral or basic, implying that it would be difficult for charge repulsion between the membrane and the charged NOM. It should be noted that hydrophobic acids exhibit hydrophobicity, due to their aromatic structure, as well as from their ionizable hydrophobic functional groups. 
The SUVA value of N-COM was related to the NOM MW, as the NOM with higher aromatic structures (high SUVA) generally exhibited larger MW. However, COM showed the lower SUVA value, although its MW was the largest. It was believed that the representative materials in the COM were aliphatic carbohydrates (i.e, amino sugar, polysaccharide and so on). Aliphatic carbohydrates usually have high MW, but low UVA values.

Table 4 shows the acidities of HP-NOM (XAD-8 isolate) and TL-NOM (XAD-4 isolate). Both HP-NOM and TL-NOM exhibited higher carboxylic acidity than the hydroxyl acidity although TL-NOM showed lower values than HP-NOM for both carboxyl and hydroxyl acidities.

\subsection{Adsorption Kinetic Tests}

To determine the reaction time for the measurement of the apparent charge of each NOM, detailed adsorption kinetic experiments were carried out with different NOM concentrations (50, 100 and $200 \mathrm{mg} / \mathrm{l})$. AL-NOM was added in pure water and monitored over time. Figure 1 shows a slightly lower NOM adsorption by the AIX membrane at higher NOM concentration. The AL-NOM adsorption by AIX membrane at different AL-NOM concentrations is shown in Figure 2. After 16 hours, it was found that approximately 3 4\% of the AL-NOM was adsorbed on to the AIX membrane. 


\subsection{Determination of apparent charge of various NOM sources}

Figure 3 shows the NOM concentrations in the membrane phase against applied NOM concentrations for each NOM source. As expected, the amount of NOM absorbed was proportional to the initial NOM concentrations. The total AL-NOM mass absorbed was highest while that of NR-NOM was the lowest. Because the free ions of the AIX membrane were chloride ions (negative charge), the higher adsorption is an indication of higher apparent charge. Table 5 shows the apparent charge and the selectivity coefficient of the three different NOM calculated using eq. (2). The results in Figure 3 and table 5 suggest higher adsorption to AIM membrane for higher apparent charge and consequently higher membrane fouling potential..

\subsection{Determination of apparent charge of various NOM structures}

The isolated NOM such as the COM, HP-NOM and TL-NOM had relatively high conductivities since $0.1 \mathrm{M} \mathrm{HCl}$ and $0.1 \mathrm{M} \mathrm{NaOH}$ solutions were used during the fractionation. According to our previous study, the NOM adsorption was significantly affected by the ionic strength and so the conductivity was alleviated using electro dialysis (ED) processes [14]. The electrodialyzer (TS-1, Tokuyama Corp., Japan) used in this study was able to accommodate 5 CMX and AMX cell pairs, with an active surface area of $100 \mathrm{~cm}^{2}$ (NEOSEPTA, Japan). A $0.05 \mathrm{M} \mathrm{NaCl}$ solution (5 liters) was 
circulated as a concentrated solution, and $3.0 \mathrm{wt} \% \mathrm{Na}_{2} \mathrm{SO}_{4}(800 \mathrm{ml})$ as an electrode rinse solution while $0.1 \mathrm{M} \mathrm{NaCl}$ solution (5 liters) was used as a dilution solution. The flow rates of both the dilute and concentrated solutions were adjusted, in the range 0.7$0.8 \mathrm{l} / \mathrm{min}$, with a direct constant current of 0.6 A unless otherwise stated. After operating the ED process, the conductivity of the NOM decreased from $11.4-12.3 \mathrm{mS} / \mathrm{cm}$ to $0.011-0.021 \mathrm{mS} / \mathrm{cm}$.

Figure 4 shows the concentrations in the membrane phase, with respect to different applied concentrations of each NOM structure. The amount of adsorbed NOM by AIX membrane was proportional to the initial NOM concentrations, similar to result in Figure 3. The total mass absorbed was highest with HP-NOM and the lowest with COM. Table 6 shows the apparent charge and the selectivity coefficient of each NOM structure calculated using eq. (2). The apparent negative charge increased with increasing amounts of NOM adsorption with HP-NOM showing the highest apparent charge and COM the lowest. The HP-NOM and TL-NOM are believed to be composed of mostly hydrophobic and transphillic acids respectively, implying they were negatively charged due to the charge density of the acidic functional groups (NOM acidity). However, the COM is generally neutral or basic so the charge of the COM was relatively low as compared with HP-NOM and TL-NOM. 
Figure 5 shows the relationship between the SUVA value and the apparent charge of each NOM. The results indicate a relatively good relationship between SUVA and the apparent NOM charge. The apparent charge of the NOM increased with increasing SUVA values, implying that the higher hydrophobic NOM has relatively higher apparent charges. SUVA s a good indicator of the humic fraction of NOM and is used as surrogate measure for NOM aromacity [4]. It can be concluded that higher SUVA value is an indication of higher apparent charge and therefore greater potential for membrane fouling due to the presence of NOM.

\section{CONCLUSIONS}

The apparent charges of different NOM were determined using AIX membrane and selectivity coefficient which showed good correlation with SUVA values. However, it should be noted that this NOM charge is not an absolute charge but an apparent charge with respect to an individual AIX membrane with a given ion-exchange capacity. Moreover, this charge may change as the solution chemistry alters, in terms of $\mathrm{pH}$ and ionic strength. Thus, the apparent charge of the NOM can be calculated for various $\mathrm{pH}$ and ionic strength conditions, and this concept of apparent charge can be used as important information of NOM in the field of membrane, as well as in other drinking 
water treatment processes.

\section{ACKNOWLEDGEMENTS}

This research was supported as the joint collaboration between Incheon Development Institute (IDI) and University of Sydney, Technology (UTS).

\section{REFERENCES}

1. Wang, L.L. Song. 1999. Flux Decline in Crossflow Microfiltration and Ultrafiltration: Experimental Verification of Fouling Dynamics. J. Membr. Sci. 160(1999): p. 41.

2. Schäfer, A.I., U. Schwicker, M.M. Fischer, A.G. FaneT.D. Waite. 2000. Microfiltration of colloids and natural organic matter. J. Membr. Sci. 171(2): p. 151.

3. Lin, C.-F., T.-Y. LinO.J. Hao. 2000. Effects of humic substance characteristics on UF performance. Water Res. 34(4): p. 1097.

4. Weishaar, J.L., G.R. Aiken, B.A. Bergamaschi, M.S. Fram, R. FujiiK. Mopper. 2003. Evaluation of Specific Ultraviolet Absorbance as an Indicator of the Chemical Composition and Reactivity of Dissolved Organic Carbon. Environ. Sci. Technol. . 37(20): p. 4702.

5. Cho, J., G. AmyJ. Pellegrino. 1999. Membrane filtration of natural organic matter: initial comparison of rejection and flux decline characteristics with ultrafiltration and nanofiltration membranes. Water Res. 33(11): p. 2517.

6. Cho, J., G. AmyJ. Pellegrino. 2000. Membrane filtration of natural organic matter: factors and mechanisms affecting rejection and flux decline with charged ultrafiltration (UF) membrane. J. Membr. Sci. 164(1-2): p. 89.

7. Amy, G.J. Cho. 1999. Interactions between natural organic matter (NOM) and 
membranes: Rejection and fouling. Water Sci. Technol. 40(9): p. 131.

8. Zularisam, A.W., A.F. IsmailR. Salim. 2006. Behaviours of natural organic matter in membrane filtration for surface water treatment -- a review. Desal. 194(1-3): p. 211.

9. Seidel, A.M. Elimelech. 2002. Coupling between chemical and physical interactions in natural organic matter (NOM) fouling of nanofiltration membranes: implications for fouling control. J. Membr. Sci. 203(1-2): p. 245.

10. Hong, S.M. Elimelech. 1997. Chemical and physical aspects of natural organic matter (NOM) fouling of nanofiltration membranes. J. Membr. Sci. 132(1997): p. 159.

11. Hong, S., R.S. FaibishM. Elimelech. 1997Journal of Colloid and Interface Science. Kinetics of Permeate Flux Decline in Crossflow Membrane Filtration of Colloidal Suspensions. J. Col. Inter. Sci. 196(1997): p. 267.

12. Mulder, M. 1997. Basic principles in membrane technology: Kluwer Academic Publishers.

13. Kim, D.H., S. LeeJ. Cho. 2000. Selectivity and adsorptivity of various anions in ion-exchange membranes. in Prod. of WQTC 2000. Salts Lake City, UT. Nov. 2000.

14. Kim, D.H., J. ChoS.H. Moon. 2003. Transport Aspect of Natural Organic Matter (NOM) in Ion-exchange Membrane for Water Treatment. Desal. 151(2003): p. 11.

15. Lee, E.G., S.H. Moon, Y.K. Chang, I.K. YooH.M. Chang. 1998. Lactic acid recovery using two-stage electrodialysis and its modeling. J. Membr. Sci. 145(1998): p. 53.

16. Lee, H.J. 1996. Pretreatment and membrane fouling in electrodialysis of ferentation Waste, in MS Thesis. K-JIST, Korea.

17. Miyyoshi, H. 1998. Diffusion coefficients of ions through ion exchange membrane in donnan dialysis using ions of different Valence. J. Membr. Sci. 141(1998): p. 101.

18. Shon, H.K., S. Vigneswaran, R.B. Aim, H.H. Ngo, I.S. KimJ. Cho. 2005. Influence of Flocculation and Adsorption as Pretreatment on the Fouling of Ultrafiltration and Nanofiltration Membranes: Application with Biologically Treated Sewage Effluent. Environ. Sci. Technol. 39(10): p. 3864.

19. Aiken, G.R., D.M. McKnight, K.A. HornE.M. Thurman. 1992. Isolation of hydrophilic organic acids from water using nonionic macroporous Resins. Org. Geochem. 18(1992): p. 567.

20. Lee, S., G. ParkJ. Cho. 2000. A new characterization method for membrane pore-size distribution using fractional rejection of polyethylene glycol (FR-PEG). 
in Prod. of NAMS 2000. Boulder Co May 2000.

21. Leenheer, J.A.N.T. I. 1984. A filtration and column adsorption system for on site concentration and fractionation of organic substances from large volumes of water. U. S. Geological Survey Water-Supply Paper 2230(1984). 


\section{LIST OF TABLES}

Table 1: Characteristics of AIX membrane

\begin{tabular}{l|l}
\hline Membrane Model Code & AMX \\
\hline \hline Type & Strong base (anion permeable $\mathrm{Cl}^{-}$form) \\
\hline Electric Resistance & \\
\hline (ohm-cm ${ }^{2}$ ) & $2.5 \sim 3.5$ \\
\hline Water Content & $0.25 \sim 0.3$ \\
\hline g H2O/g dried membrane) & \\
\hline Exchange Capacity & $1.4 \sim 1.7$ \\
\hline (meta potential at pH 7 & \\
\hline Thickness (mm) & $0.16 \sim 0.18$ \\
\hline
\end{tabular}

* Data provided by the manufacturer 
Table 2: Molecular weight of NOM for NR-NOM, SR-NOM and AC-NOM

\begin{tabular}{l|l|l|l}
\hline Source & $\mathbf{M}_{\mathbf{n}}$ (number & $\mathbf{M}_{\mathbf{w}}$ (weight & Polydiversity \\
\hline \hline Nakdong River & (Da) & averaged MW) & $\left.\mathbf{( M}_{\mathbf{w}} / \mathbf{M}_{\mathbf{n}}\right)$ \\
NOM (NR-NOM) & $1242 \pm 35$ & $1565 \pm 52$ & 1.26 \\
\hline Suwannee River & & & \\
NOM & $2320 \pm 62$ & $3572 \pm 93$ & 1.54 \\
\hline (SR-NOM) & & & \\
\hline Aldrich NOM & & & \\
\hline
\end{tabular}


Table 3: Concentration of different fractions in NR-NOM

\begin{tabular}{|c|c|c|c|c|c|}
\hline & $\begin{array}{l}\text { Weight } \\
\text { average MW } \\
\text { (Da) }\end{array}$ & $\begin{array}{l}\text { DOC (mg } \\
\text { C/L) }\end{array}$ & $\mathrm{UVA}_{254}\left(\mathrm{~cm}^{-1}\right)$ & $\begin{array}{l}\text { SUVA } \\
\left(\mathrm{L} \cdot \mathrm{mg}^{-1} \mathrm{~m}^{-1}\right)\end{array}$ & $\begin{array}{l}\text { Mass } \\
\text { fraction } \\
\text { (\%) }\end{array}$ \\
\hline Raw & $1242 / 1565$ & $3.07 \pm 0.05$ & $0.0812 \pm 0.003$ & 2.71 & 100 \\
\hline $\mathrm{COM}$ & $2420 / 3850$ & $3.30 \pm 0.06$ & $0.0551 \pm 0.001$ & 1.80 & 18.7 \\
\hline HP & $1430 / 2590$ & $3.26 \pm 0.03$ & $0.0921 \pm 0.004$ & 3.04 & 34.3 \\
\hline $\mathrm{TL}$ & $1180 / 1630$ & $3.14 \pm 0.04$ & $0.0807 \pm 0.003$ & 2.57 & 14.5 \\
\hline HL & $1090 / 1420$ & $1.64 \pm 0.01$ & $0.0310 \pm 0.001$ & 1.89 & 18.6 \\
\hline Loss & - & - & - & - & 13.9 \\
\hline
\end{tabular}


Table 4: Functionality information of NOM

\begin{tabular}{lcc}
\hline Source & $\begin{array}{c}\text { Carboxyl group }\left(\mathbf{C O O H}^{-}\right) \\
\text {(meq/gC) }\end{array}$ & $\begin{array}{l}\text { Hydroxyl group }\left(\mathbf{O H}^{-}\right) \\
(\mathbf{m e q} / \mathbf{g C})\end{array}$ \\
\hline \hline HP-NOM & $13.1 \pm 0.73$ & $16.5 \pm 1.12$ \\
TL-NOM & $11.5 \pm 0.95$ & $10.7 \pm 0.75$ \\
\hline
\end{tabular}


Table 5: Apparent charge and selectivity coefficient of various NOM sources

Source Apparent charge Selectivity coefficient

$\begin{array}{lll}\text { AL-NOM } & -6.04 & 0.026 \\ \text { SR-NOM } & -2.14 & 0.094 \\ \text { NR-NOM } & -1.71 & 0.082\end{array}$


Table 6: Apparent charge and selectivity coefficient of various NOM structures

\begin{tabular}{lll}
\hline Source & Apparent charge & Selectivity coefficient \\
\hline \hline COM & -1.70 & 0.089 \\
\hline HP-NOM & -3.17 & 0.087 \\
\hline TL-NOM & -2.01 & 0.084 \\
\hline
\end{tabular}




\section{LIST OF FIGURES}

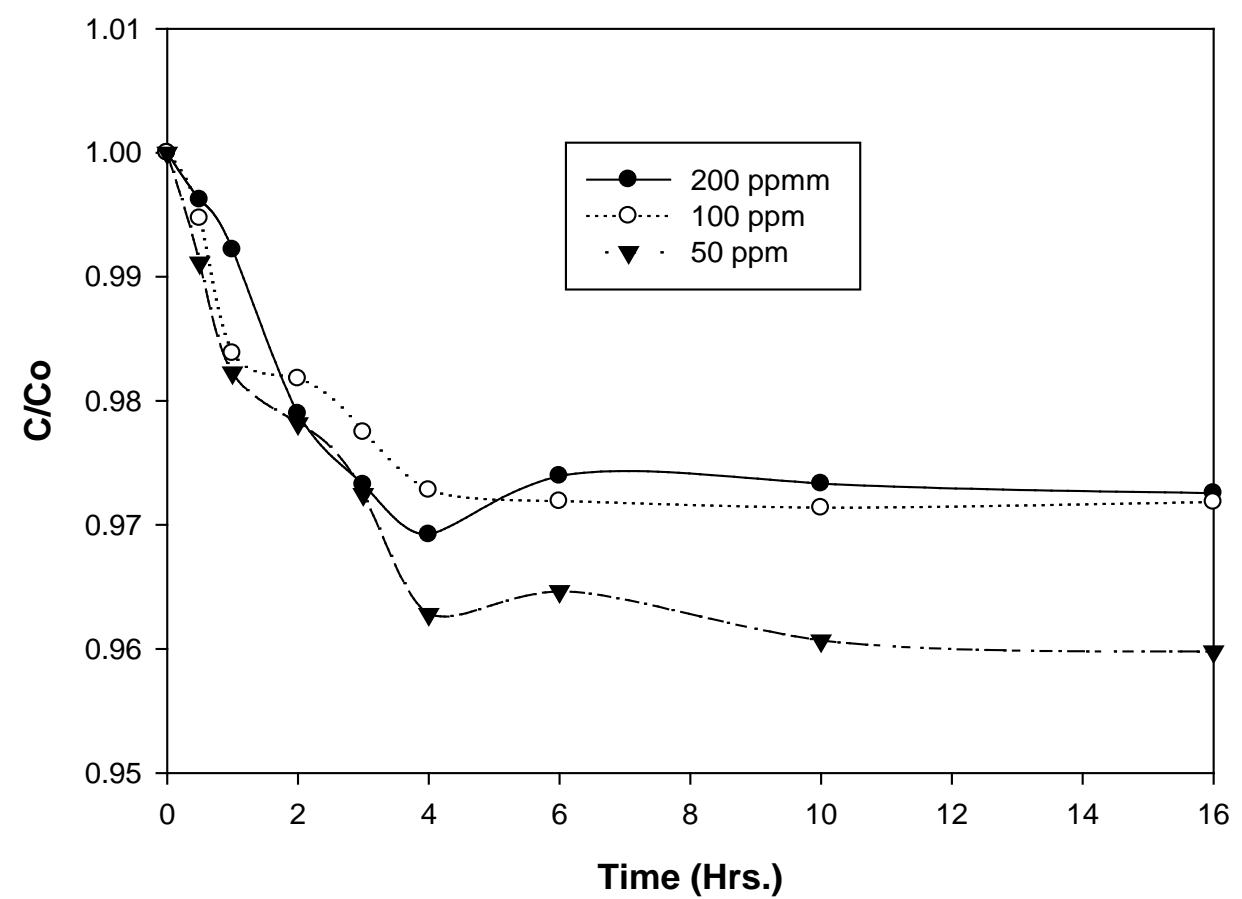

Figure 1: Adsorption kinetic test of Al-NOM on the AIX membrane. 


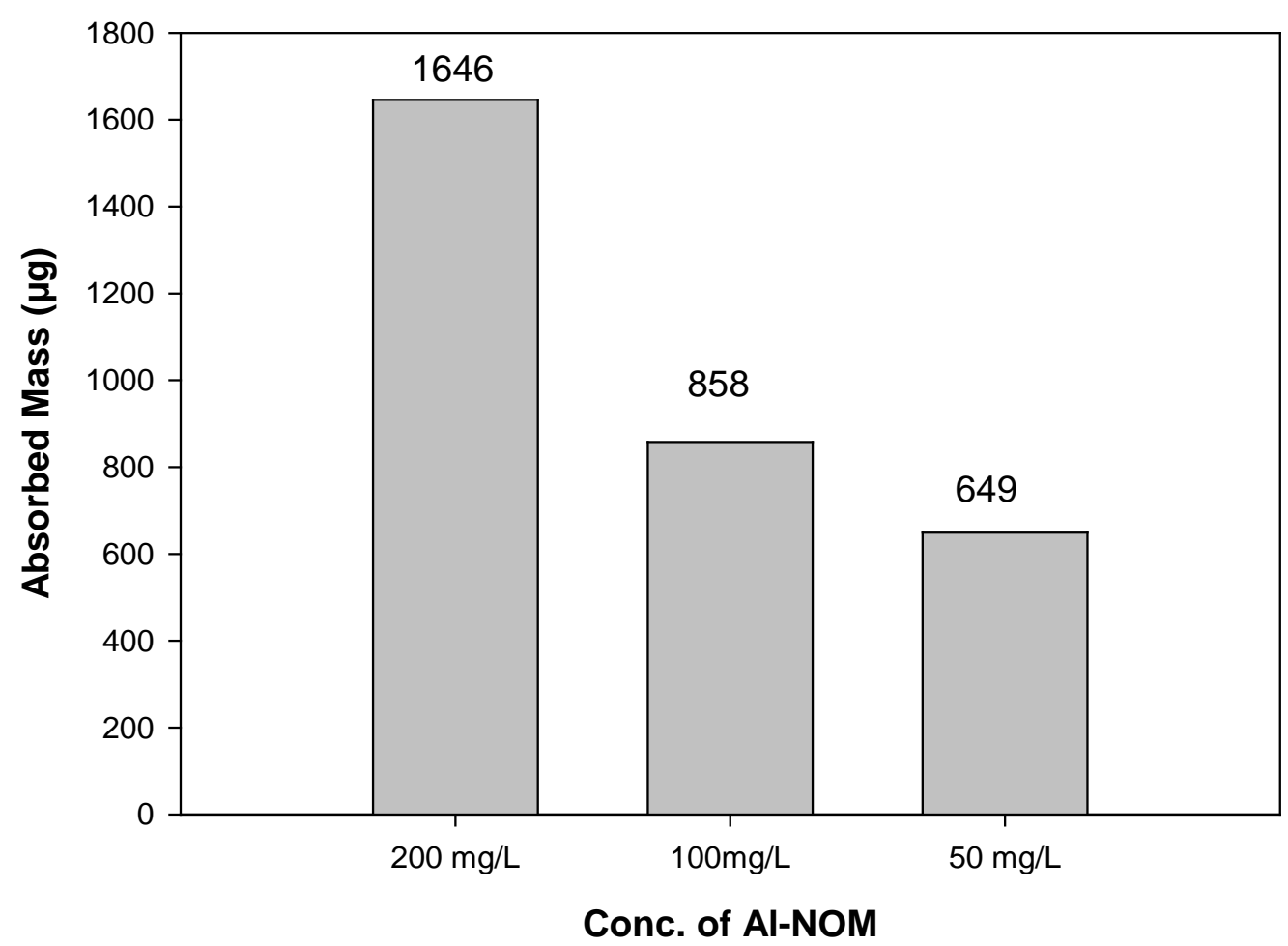

Figure 2: Total adsorbed mass of Al-NOM on the AIX membrane. 


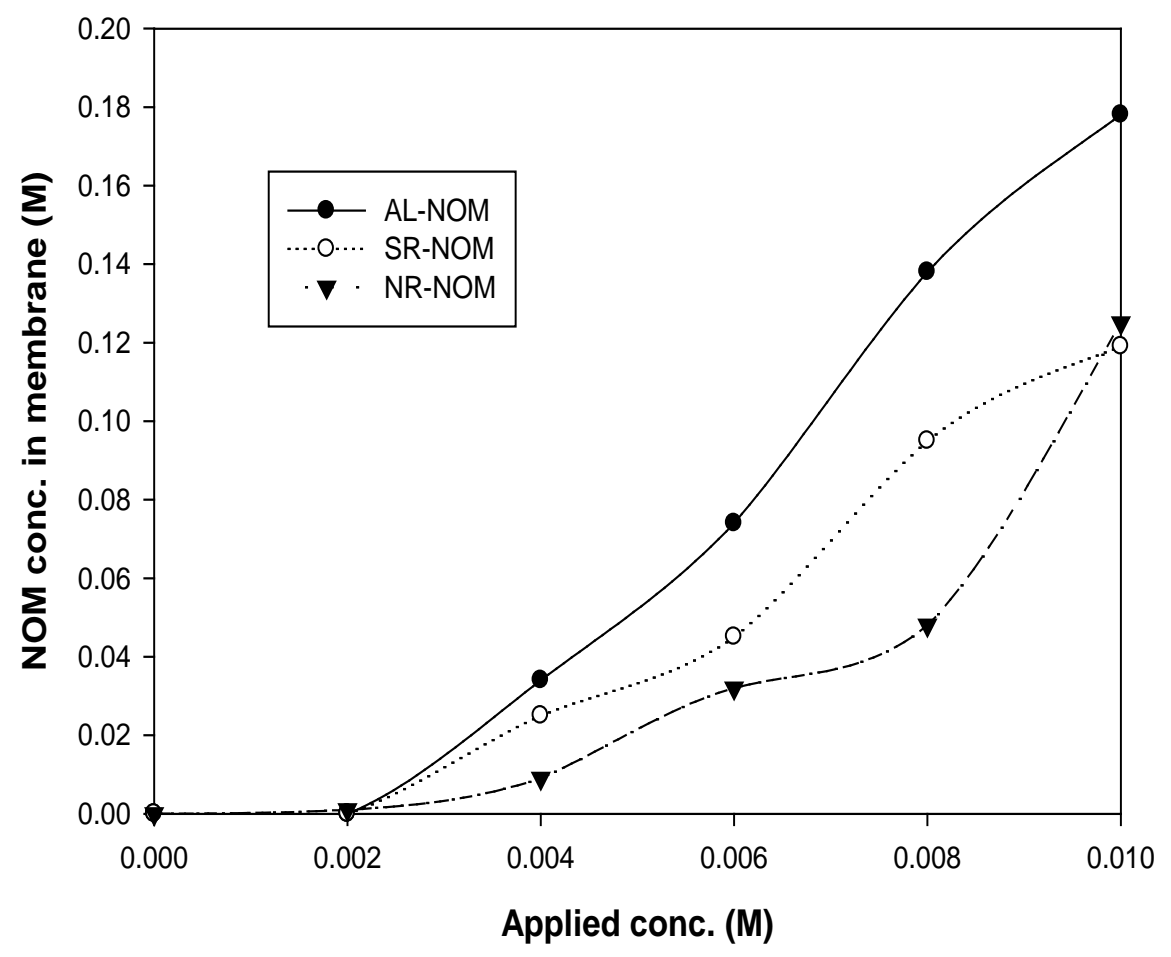

Figure 3: Concentration of NOM in membrane phase with respect to NOM

concentration from different NOM sources. The concentrations in M (moles/L) have been arrived after the molecular weight of each NOM source was determined from HPLC-SEC analysis. 


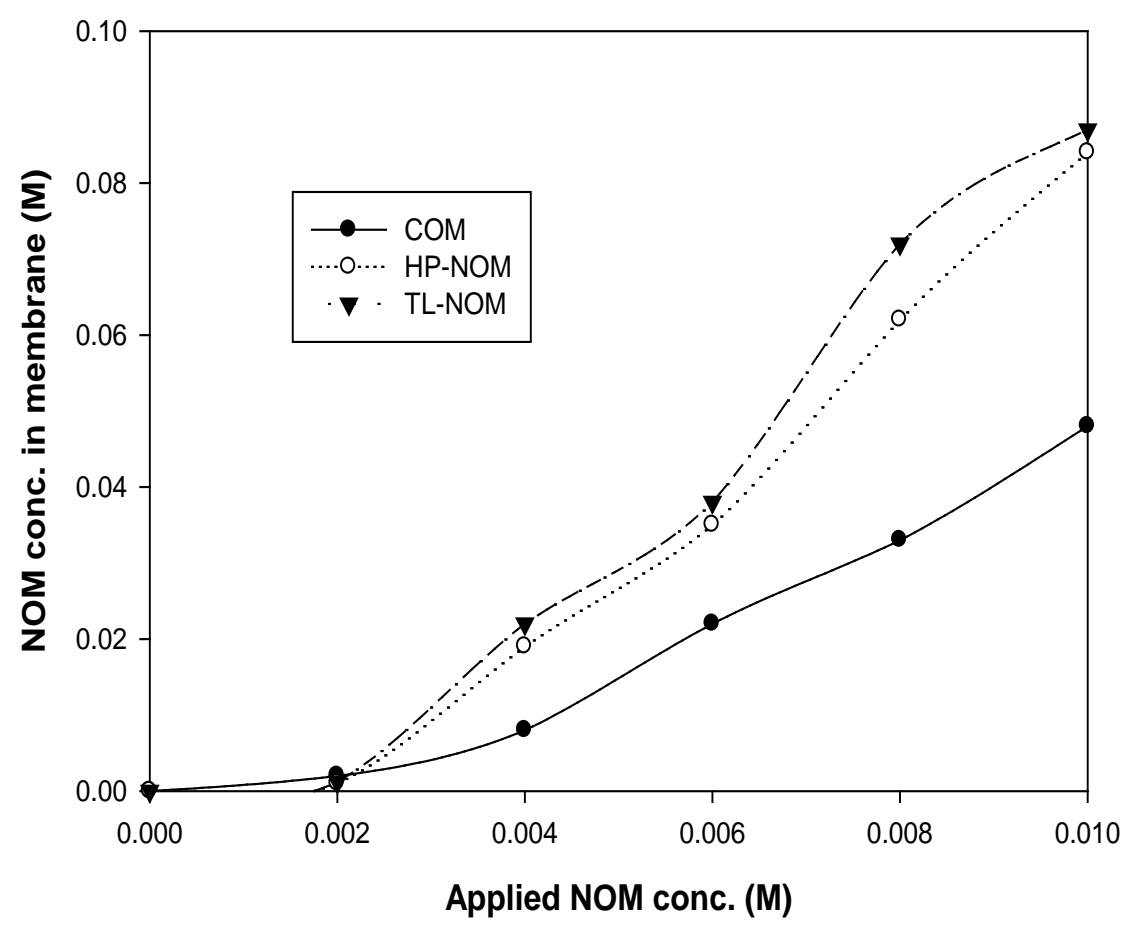

Figure 4: NOM concentration in membrane phase with respect to NR-NOM

concentrations with different NOM structures. The concentrations in M (moles/L) have been arrived after the molecular weight of each NOM structure was determined from HPLC-SEC analysis. 


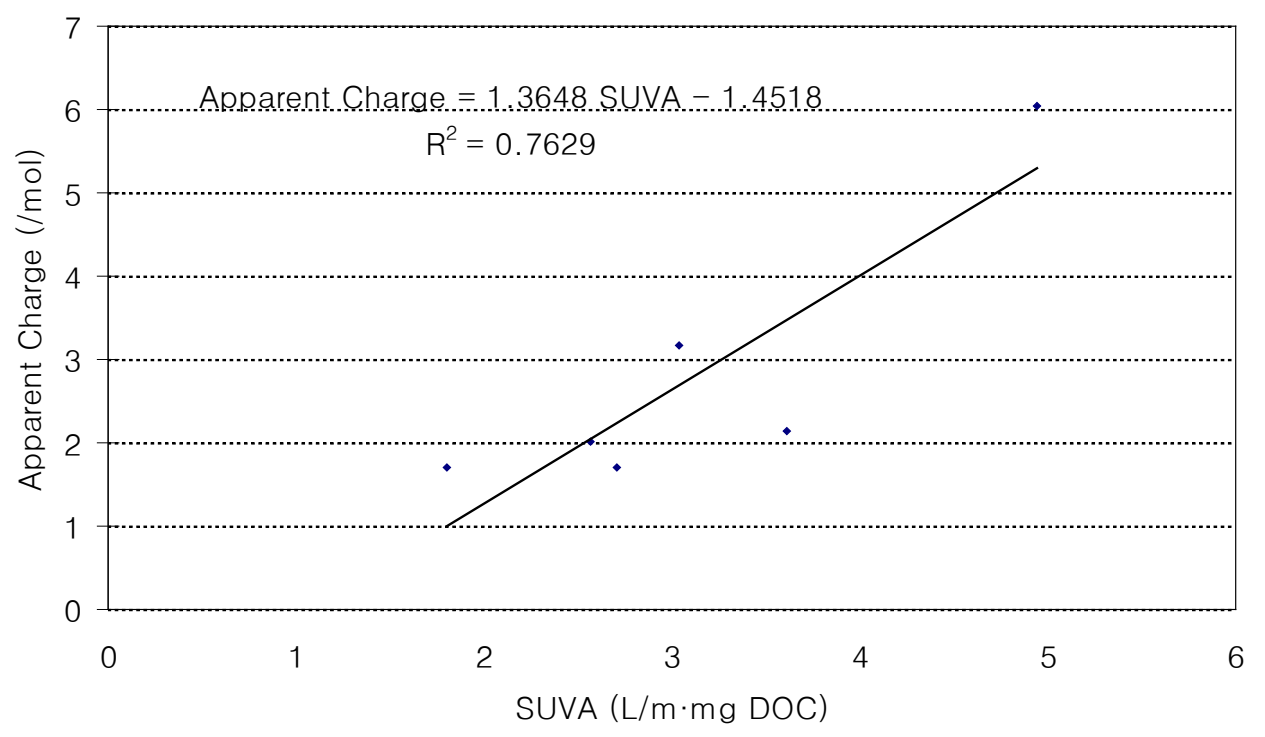

Figure 5: Relationship between NOM SUVA and apparent charge. 